\title{
Research on the Fuel Saving Effect of Idle Parking car Based on NEDC System Analysis
}

\author{
Jiapeng $\mathrm{Lu}^{1,2, \mathrm{a}}$, Youde $\mathrm{Li}^{2}$ and Xiangsheng $\mathrm{Dai}^{3}$ \\ ${ }^{1}$ FAW car Company Limited, Changchun city, Jilin Province, 130048 \\ ${ }^{2}$ College of automobile Engineering, Jilin University, Changchun city, Jilin Province, 130022 \\ ${ }^{3}$ China FAW Group Corporation R\&D Center, Changchun city, Jilin Province, 130011 \\ alu_jiapeng@163.com
}

Keywords: NEDC technology; Idle start stop system; Instantaneous fuel consumption.

\begin{abstract}
Objective: To study the technology of auxiliary motor starting and stopping of the direct injection gasoline engine, and analyze the effect of the idle start stop system and oil saving energy. Method: the fuel saving effect analysis of the fuel saving effect of the system is analyzed by the multiple model. Process: we in the downtown and suburban stop system to open and close the NEDC fuel consumption record results, typical conditions stop system NEDC drive cycle fuel saving effect curve analysis, and instantaneous fuel consumption curve comprehensive comparative analysis. Conclusion: through data analysis, we can know that the average vehicle parking time is more than 9S, the system can reduce the fuel consumption of vehicles; for these two models, starting fuel consumption is high.
\end{abstract}

\section{Introduction}

In recent years, the environment and climate change, energy security and other issues have become increasingly prominent, energy-saving emission reduction work has become one of the important work of the government[1,2,3,4]. As one of the main sources of energy consumption and pollutant emissions, the traditional automobile needs to develop the technology to reduce energy consumption and emissions[5]. Among them, the cylinder direct injection gasoline engine has good power and economy, as well as low CO2 emissions, is a very good development potential of the traditional car models. In this paper[6], by constructing the drum test bench, in NEDC driving conditions on particle emission measurement study under different conditions of particulate emission characteristics.

\section{Development Status of Direct Injection Technology in Cylinder}

The world's R \&amp; D capabilities of the auto companies are increasing their efforts to develop and actively launch vehicles equipped with this advanced technology, excellent performance. At present, the development of fruitful results[7,8], the continuous improvement of the technology, fuel efficiency continues to improve, many products have been put into production. Now the world's second generation GDI engine is very well put into commercial use, more than $50 \%$ of the market share, but also continue to grow. Domestic also launched a different model of the GDI car.

\section{The New European Driving Cycle}

The main characteristics of the EDC cycle are the test time is short, the mileage is small, the speed is low, the speed is low, the speed is low, and the influence of the environmental temperature on the fuel consumption is not considered.

NEDC operating mode is divided into two parts: urban working condition (City) and the working condition (Highway). The working condition of the urban district is composed of four operating cycle units, that is, the same process is repeated four times. In the test process, the maximum speed of $50 \mathrm{~km} / \mathrm{h}$, the average speed of $19 \mathrm{~km} / \mathrm{h}$, each cycle time is 195 seconds, a total of traveling $4.052 \mathrm{~km}$ distance. 
If the experimental data is carefully observed, the majority of the time in the NEDC operating mode will be at a constant speed. The test content did not take full account of the urban traffic jams vehicle stop and go, suburban test is speed and acceleration test, do not have much practical significance.

Another drawback of the NEDC mode is without considering the effect of environment temperature on fuel consumption, automobile air conditioner switch will greatly affect the fuel consumption data. For example, a uniform $20 \mathrm{~km} / \mathrm{h}$ of the car, open air conditioning and air conditioning is not open a hundred kilometers fuel consumption difference will exceed 2 liters.

\section{The Data Analysis}

Evaluation and Analysis of Audi A6L Models.

Table 1. The basic vehicle information of Audi A6L

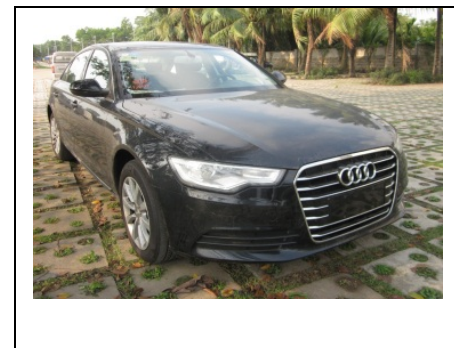

\begin{tabular}{|l|c|}
\hline Vehicle model & Audi A6L \\
\hline Engine type & $\begin{array}{c}\text { straight line four cylinder } \\
\text { turbocharged cylinder direct } \\
\text { injection engine }\end{array}$ \\
\hline Displacement & 2.0L \\
\hline Rated power & 132kW@4000-6000rpm \\
\hline Maximum torque & 320Nm@1500-3900rpm \\
\hline Transmission form & 8CVT \\
\hline
\end{tabular}

Table 2. Comparison of fuel consumption for different driving cycles of Audi A6L (mL)

\begin{tabular}{|c|c|c|c|c|c|}
\hline & Idle & Acceleration & Uniform & Deceleration & Cumulative \\
\hline Stop mode & 48.8 & 369.0 & 298.7 & 47.6 & 764.1 \\
\hline Non stop mode & 106.4 & 359.0 & 296.4 & 49.0 & 810.8 \\
\hline
\end{tabular}

Table.3 Comparison of fuel consumption of different driving cycles of Audi A6L

\begin{tabular}{|c|c|c|c|c|c|}
\hline & Idle & Acceleration & Uniform & Deceleration & Cumulative \\
\hline Stop mode & $6.4 \%$ & $48.3 \%$ & $39.1 \%$ & $6.2 \%$ & $100 \%$ \\
\hline Non stop mode & $13.1 \%$ & $44.3 \%$ & $36.6 \%$ & $6.0 \%$ & $100 \%$ \\
\hline
\end{tabular}

Analysis of typical working condition of start stop system of fuel saving effect

He start stop system of oil saving effect analysis. Analysis results are shown in Table 4.

Table 4. Audi A6L NEDC typical start stop system of fuel saving effect

\begin{tabular}{|c|c|c|c|c|}
\hline \multicolumn{2}{|l|}{ Time slot } & \multirow{2}{*}{$\begin{array}{l}\text { Total fuel } \\
\text { consumption } \\
\text { (mL) } \\
32.39\end{array}$} & \multirow{3}{*}{$\begin{array}{l}\text { Idle fuel } \\
\text { consumption } \\
(\mathrm{L} / \mathrm{h}) \\
1 \\
1.37\end{array}$} & \multirow{2}{*}{$\begin{array}{l}\text { Once the fuel consumption } \\
\text { is equivalent to the idle time } \\
\text { (s) } \\
8.6\end{array}$} \\
\hline \multirow{2}{*}{ 85-143s } & Stop & & & \\
\hline & Non-stop & 37.12 & & \\
\hline \multirow{2}{*}{ 280-338s } & Stop & 29.84 & \multirow{2}{*}{1.21} & \multirow{2}{*}{5.7} \\
\hline & Non-stop & 34.97 & & \\
\hline \multirow{2}{*}{ 475-533s } & Stop & 28.65 & \multirow{2}{*}{1.13} & \multirow{2}{*}{5.3} \\
\hline & Non-stop & 33.59 & & \\
\hline \multirow{2}{*}{$670-728 s$} & Stop & 28.62 & \multirow{2}{*}{1.05} & \multirow{2}{*}{8.9} \\
\hline & Non-stop & 32.16 & & \\
\hline
\end{tabular}




\section{Evaluation and Analysis of Red H7 Blue Passers.}

Table 5. Red H7 blue passers vehicle basic information

\begin{tabular}{|l|l|c|}
\hline & Vehicle model & \multicolumn{1}{c|}{ Red H7 blue passers } \\
\hline Engine type & $\begin{array}{c}\text { straight line four cylinder turbocharged } \\
\text { cylinder direct injection engine }\end{array}$ \\
\hline Displacement & 2.0L \\
\hline Rated power & 145kW@5500rpm \\
\hline $\begin{array}{l}\text { Maximum } \\
\text { torque }\end{array}$ & 280Nm@2000-4000rpm \\
$\begin{array}{l}\text { Transmission } \\
\text { form }\end{array}$ & 7DCT \\
\hline
\end{tabular}

Table 6. Red flag H7 blue way different driving cycle fuel consumption contrast (unit: $\mathrm{mL}$ )

\begin{tabular}{|c|c|c|c|c|c|}
\hline & Idle & Acceleration & Uniform & Deceleration & Cumulative \\
\hline Stop mode & 38.1 & 377.7 & 385.9 & 56.2 & 857.8 \\
\hline Non stop mode & 112.7 & 404.9 & 372.8 & 44.5 & 934.9 \\
\hline
\end{tabular}

Table 7. Comparison of fuel consumption ratio of different driving cycles of red flag H7 Blue Road

\begin{tabular}{|c|c|c|c|c|c|}
\hline & Idle & Acceleration & Uniform & Deceleration & Cumulative \\
\hline Stop mode & $4.4 \%$ & $44.0 \%$ & $45.0 \%$ & $6.5 \%$ & $100 \%$ \\
\hline Non stop mode & $12.1 \%$ & $43.3 \%$ & $39.9 \%$ & $4.8 \%$ & $100 \%$ \\
\hline
\end{tabular}

Analysis of typical working condition of start stop system of fuel saving effect

Typical conditions in the NEDC condition, the fuel saving effect of start stop system. Analysis results are shown in Table 8.

Table 8. Red H7 blue passers NEDC typical start stop system of fuel saving effect

\begin{tabular}{|c|c|c|c|c|}
\hline \multicolumn{2}{|l|}{ Time slot } & $\begin{array}{l}\text { Total fuel } \\
\text { consumption }(\mathrm{mL})\end{array}$ & $\begin{array}{l}\text { Idle fuel } \\
\text { consumption }(\mathrm{L} / \mathrm{h})\end{array}$ & $\begin{array}{l}\text { Once the fuel consumption is } \\
\text { equivalent to the idle time (s) }\end{array}$ \\
\hline \multirow{2}{*}{$85-143 s$} & Stop & 33.3 & \multirow{2}{*}{1.76} & \multirow{2}{*}{-3.8} \\
\hline & Non-stop & 45.4 & & \\
\hline \multirow{2}{*}{ 280-338s } & Stop & 31.1 & \multirow{2}{*}{1.41} & \multirow{2}{*}{-2.3} \\
\hline & Non-stop & 40.3 & & \\
\hline \multirow{2}{*}{$475-533 s$} & Stop & 29.2 & \multirow{2}{*}{1.20} & \multirow{2}{*}{2.6} \\
\hline & Non-stop & 35.4 & & \\
\hline \multirow{2}{*}{$670-728 \mathrm{~s}$} & Stop & 30.2 & \multirow{2}{*}{1.08} & \multirow{2}{*}{7.4} \\
\hline & Non-stop & 34.3 & & \\
\hline
\end{tabular}

\section{Conclusion}

The equivalent of a starting fuel consumption equivalent to idle time (s) at 4 time intervals, the results are obtained as the result of Table 9.

Table 9. The average value of a starting fuel consumption equivalent to the idle time

\begin{tabular}{|l|c|c|c|c|c|c|}
\hline Models & Mira & Audi A6L & Fawkes & Audi A5 & Red flag H7 & Volvo S60 \\
\hline$\overline{\mathrm{t}}(\mathrm{s})$ & 8.9 & 7.1 & 16.6 & 5.5 & 1.0 & 14.8 \\
\hline
\end{tabular}

$\overline{\mathrm{t}}$ - The average value of a starting fuel consumption equivalent to the idle time

From Table 9,

1) for the general vehicle, such as the big hair Mira, Audi A6L, Audi A5, as long as the idle speed stop time is more than 9s, the system can reduce vehicle fuel consumption;

2) for Fawkes and S60, the starting fuel consumption is higher, the starting and stopping system needs to be further improved;

3) for the red flag H7 blue way, increase the fuel consumption of the starting and stopping system to achieve $10 \%$, the calculation of the equivalent of a starting fuel consumption is equivalent to the idle time, the problem is suspected to be a non-starting mode of fuel injection calibration. 


\section{References}

[1] POGUE G A, SARTORIS W L, HILL N E D C. A Generalized Cash Flow Approach to Short-Term Financial Decisions. The Journal of Finance, 1983, 38(2): 349-360.

[2] Karavalakis G, Alvanou F, Stournas S, et al. Regulated and unregulated emissions of a light duty vehicle operated on diesel/palm-based methyl ester blends over NEDC and a non-legislated driving cycle. Fuel, 2009, 88(6): 1078-1085.

[3] Bermúdez V, Lujan J M, Pla B, et al. Comparative study of regulated and unregulated gaseous emissions during NEDC in a light-duty diesel engine fuelled with Fischer Tropsch and biodiesel fuels. Biomass and Bioenergy, 2011, 35(2): 789-798.

[4] Kothuri R K V, Ravada S, Abugov D. Quadtree and R-tree indexes in oracle spatial: a comparison using GIS data//Proceedings of the 2002 ACM SIGMOD international conference on Management of data. ACM, 2002: 546-557.

[5] Demuynck J, Bosteels D, De Paepe M, et al. Recommendations for the new WLTP cycle based on an analysis of vehicle emission measurements on NEDC and CADC. Energy Policy, 2012, 49: 234-242.

[6] Dixon R. Venture capitalists and the appraisal of investments. Omega, 1991, 19(5): 333-344.

[7] Wanker R J, Wurzenberger J C, Schuemie H A. Three-way catalyst light-off during the NEDC test cycle: fully coupled $0 \mathrm{D} / 1 \mathrm{D}$ simulation of gasoline combustion, pollutant formation and aftertreatment systems. SAE Technical Paper, 2008.

[8] Merkisz J, Fuc P, Lijewski P, et al. The Comparison of the Emissions from Light Duty Vehicle in On-road and NEDC Tests. SAE Technical Paper, 2010. 